\title{
КОНЦЕПТУАЛЬНАЯ МОДЕЛЬ УПРАВЛЕНИЯ МАРКЕТИНГОМ ИННОВАЦИЙ В СФЕРЕ ГОРОДСКИХ ПАССАЖИРСКИХ ПЕРЕВОЗОК
}

\author{
(c) 2020 Калиева Ольга Михайловна \\ доктор экономических наук, доцент \\ заведующий кафедрой маркетинга и торгового дела \\ Оренбургский государственный университет, Россия, Оренбург \\ E-mail: kom34@rambler.ru \\ (c) 2020 Карелин Николай Владимирович \\ аспирант кафедры маркетинга и торгового дела \\ Оренбургский государственный университет, Россия, Оренбург \\ E-mail: karelin93@mail.ru
}

Предложена авторская концептуальная модель управления маркетингом инноваций для городских пассажирских перевозок, основанная на представленных в исследовании ключевых особенностях городских пассажирских перевозок. Для определения специфики городских пассажирских перевозок проведено исследование с применением методик SWOT и PEST анализа. Установлено, что слабыми сторонами городских пассажирских перевозок являются низкий уровень оплаты труда, текучесть кадров производственного персонала, высокий износ основных фондов (подвижной состав, здания и сооружения), высокий уровень накладных расходов. К сильным сторонам относятся соблюдение действующих требований нормативных документов в части обеспечения безопасности дорожного движения, внедрение передовых технологий, стабильность кадрового состава. Полученные результаты дают возможность улучшения качества обслуживания потребителей, повышения эффективности использования транспортных средств и сокращения материальных и трудовых затрат на эксплуатацию.

Ключевые слова: маркетинг инноваций городских пассажирских перевозок, модель, функции инноваций городских пассажирских перевозок.

На предприятиях любой формы деятельности с постоянно протекающими сложными организационными процессами, характеризующими их функционирование и развитие, необходимы трансформационные переходы, выраженные в стратегических задачах развития, которые позволят придерживаться устойчивого положения на рынке, оставаться конкурентоспособными. На современном этапе развития экономических отношений стратегические задачи развития, как правило, включают в себя создание новых продуктов, отвечающих современным требованиям и стандартам. Именно благодаря реализации стратегических задач развития появляются предпосылки появления новых инновационных продуктов.

Актуальность процесса инновационной деятельности предполагает определенное внимание к вопросам инновационного развития предприятий, разработку новых подходов и аспектов их исследования, связанных с тем, что фундаментальные изменения в экономике должны сочетаться с интересом к инновационному развитию ее непосредственных участников. Предприятие может быть инновационным и перспективным к развитию, если тенденция этого развития обусловлена комплексным продвижением всех видов инноваций [1].

В современных реалиях предприятия, понимающие новые правила маркетинга, развивают отношения непосредственно с потребителями. Основной целью маркетинга инноваций является продвижение товара или услуги, обладающих новыми свойствами. Путем внедрения новых маркетинговых методов и мероприятий, предприятия стремятся установить более тесные отношения с клиентами, что приводит их к ситуации, когда клиенты сами становятся промоутерами организации - состояние, при котором потребители лояльны к организации и рекомен- 
дуют ее своим референтным группам [2]. Помимо вышесказанного, иными целями маркетинга инноваций являются: оптимизация производства и сбыта, контроль над инновацией, проникновение на новые рынки, т.е. повышение уровня видимости и присутствия компании путем внедрения новшеств [3].

Маркетинг инноваций нацелен на продвижении новшеств, ориентированных на удовлетворение потребностей потребителей путем достижения устойчивого конкурентного преимущества и предполагает использование совершенно новых маркетинговых стратегий, маркетинговых концепций или новых маркетинговых методов, которые раннее не находили своего применения в деятельности предприятия.

Особо интересен, с точки зрения маркетинговых инноваций вопрос о необходимости применения маркетинга инноваций в транспорте, который приобретает все большее значение в организации успешной деятельности предприятий городских пассажирских перевозок. Отмечен повышенный интерес и возросшая роль «технологического» фактора как основного фактора экономического развития предприятий городских пассажирских перевозок, а степень развития инновационной сферы - науки, технологий, отраслей - оказывает прямое влияние на устойчивый экономический рост и темпы развития [4].

Одной из главных целей деятельности предприятия городских пассажирских перевозок является получение прибыли, что на данном экономическом этапе возможно только путем совершенствования выполняемых работ и расширения разновидности оказываемых услуг посредством реализации «инновационнореволюционных» разработок, позволяющих конкурировать на рынке. На наш взгляд, достижение такого рода цели возможно посредством обоснованного выбора маркетинговой стратегии, предусматривающей ориентацию управляющей подсистемы предприятия на потребителя при решении любых задач в соответствии с ситуацией на рынке. Рассматривается сопоставление возможности автотранспортного предприятия предоставлять определенные услуги или выполнять определенные работы, что обусловлено его материально-технической базой, подвижным составом, материальными и финансовы- ми ресурсами, наличием квалифицированных специалистов и персонала, рыночного спроса на данные услуги. На основании анализа внешней, внутренней среды предприятия с учетом размера маркетингового бюджета формируется маркетинговая стратегия предприятия городских пассажирских перевозок, необходимая для обеспечения не только высокого сбыта предоставляемых услуг, оказываемых предприятием, но и достаточной рентабельности производства [5].

В результате проведенного маркетингового исследования, анализа различных источников о маркетинговых стратегиях инноваций в сфере городских пассажирских перевозок выявлена необходимость в формировании общецелевой маркетинговой стратегии, предложено учитывать при формировании собственной маркетинговой стратегии факторы, влияющие на работу предприятия, разделенные на две категории: внутренние и внешние (SWOT-анализ и PESTанализ) [6]. Проведенный анализ, таблица 1, позволяет отнести к основным сильным сторонам стабильность и устойчивость предприятий городских пассажирских перевозок, к слабым высокий уровень издержек.

Основными возможностями предприятий городских пассажирских перевозок являются стабильная востребованность услуг со стороны пользователей и деловая репутация. Основные угрозы - это регулируемые государством стоимость проезда и ограниченность бюджета. Резюмируя, отметим:

1) При соотношении сильных сторон и возможностей необходимо произвести внедрение новых технологий с устойчивой финансовой поддержкой местной власти.

2) При соотношении слабых сторон и возможностей рекомендовано повысить уровень оплаты труда и компенсировать износ основных фондов за счет средств бюджета.

3) При соотношении сильных сторон и угроз следует повысить уровень качества предоставляемой услуги и изменить систему логистики.

4) При соотношении слабых сторон и угроз возможны большие убытки предприятия и дальнейшее снижение качества предоставляемых услуг.

При определении внешних факторов (политические, экономические, социальные и 
Таблища 1. Матрица SWOT-анализа предприятий городских пассажирских перевозок (составлено авторами)

\begin{tabular}{|c|c|c|}
\hline Внутренняя среда & $\begin{array}{l}\text { Возможности: } \\
\text { - стабильная востребованность } \\
\text { предоставления предприятием } \\
\text { услуг по перевозке пассажиров } \\
\text { автомобильным транспортом } \\
\text { (социально-значимые маршруты) } \\
\text { - деловая репутация предприятия } \\
\text { с поддержкой органов местного } \\
\text { самоуправления } \\
\text { - возможность реализации } \\
\text { программ развития муниципаль- } \\
\text { ного пассажирского транспорта с } \\
\text { финансовой поддержкой за счет } \\
\text { средств местного и вышестоящих } \\
\text { бюджетов }\end{array}$ & $\begin{array}{l}\text { Угрозы: } \\
\text { - высокая степень дублирования } \\
\text { муниципальных маршрутов част- } \\
\text { ным транспортом } \\
\text { - ограниченные возможности } \\
\text { бюджета по возможности выде- } \\
\text { ления субсидий предприятия на } \\
\text { частичное возмещение затрат } \\
\text { - оказание транспортных услуг по } \\
\text { государственно-регулируемым та- } \\
\text { рифам (постановление правитель- } \\
\text { ства РФ от } 7 \text { марта 1995 г. № 239) } \\
\text { - неурегулированность норма- } \\
\text { тивных документов при проведе- } \\
\text { нии конкурсных процедур }\end{array}$ \\
\hline $\begin{array}{l}\text { Сильные стороны: } \\
\text { - соблюдение действующих тре- } \\
\text { бований нормативных документов } \\
\text { в части обеспечения безопасности } \\
\text { дорожного движения, трудовые } \\
\text { гарантии (ТК) } \\
\text { - внедрение передовых тех- } \\
\text { нологий (перевод автобусов на } \\
\text { газомоторное топливо, внедрение } \\
\text { системы Глонасс, оптимизация } \\
\text { схем движения, расписаний) } \\
\text { - стабильность кадрового состава } \\
\text { (ИТР, служащие) (гарантированная } \\
\text { оплата труда, отпуск) } \\
\text { - устойчивые традиции }\end{array}$ & $\begin{array}{l}\text { - внедрение передовых тех- } \\
\text { нологий и стабильная востре- } \\
\text { бованность и стабильная вос- } \\
\text { требованность предоставления } \\
\text { предприятием услуг по перевозке } \\
\text { пассажиров повышают привлека- } \\
\text { тельность среди граждан } \\
\text { - устойчивые традиции и воз- } \\
\text { можности реализации программ } \\
\text { развития с финансовой поддерж- } \\
\text { кой позволяют строить прочную } \\
\text { современную систему на предпри- } \\
\text { ятии }\end{array}$ & $\begin{array}{l}\text { - необходимо повышать привле- } \\
\text { кательность за счет более каче- } \\
\text { ственного обслуживания } \\
\text { - изменение системы логистики }\end{array}$ \\
\hline $\begin{array}{l}\text { Слабые стороны: } \\
\text { - низкий уровень оплаты труда, } \\
\text { текучесть кадров производствен- } \\
\text { ного персонала } \\
\text { - высокий износ основных фон- } \\
\text { дов (подвижной состав, здания и } \\
\text { сооружения) } \\
\text { - высокий уровень накладных } \\
\text { расходов }\end{array}$ & $\begin{array}{l}\text { - повысить уровень оплаты труда } \\
\text { для снижения текучести кадров } \\
\text { - компенсировать износ основ- } \\
\text { ных фондов за счет средств бюдже- } \\
\text { та }\end{array}$ & $\begin{array}{l}\text { - большие убытки усугубляют фи- } \\
\text { нансовое состояние предприятия } \\
\text { до полного разорения } \\
\text { - невозможность повышения } \\
\text { уровня оплаты труда сказывается } \\
\text { на низком качестве обслуживания } \\
\text { и работоспособности работников }\end{array}$ \\
\hline
\end{tabular}


технологические) с оценкой факторов по пятибалльной шкале, расчете сумм воздействия $\mathrm{P}=13 * 0,3=3,9 ; \quad \mathrm{E}=11 * 0,3=3,3 ; \quad \mathrm{S}=10 * 0,2=2$; $\mathrm{T}=12 * 0,2=2,4$, выявлено (таблица 2):

- наиболее важными факторами внешней среды, занимающими первое место, являются политические факторы, оказывающие прямое влияние на развитие данной отрасли. Поэтому, необходимо поддержание обратной связи с государственными структурами, нацеленное на единство достижения поставленных маркетинговых целей в отрасли;

- на втором месте экономические факторы среды, от которых зависит экономическая эффективность работы предприятия;

- технологические и социальные факторы не столь сильно влияют на осуществление деятельности предприятий городских пассажирских перевозок.

Сравнительный анализ научной информации из различных источников о маркетинговой стратегии городских пассажирских перевозок выявил, что одной из маркетинговых стратегий продвижения инноваций на предприятии городских пассажирских перевозок может быть диверсификация - как стратегия, нацеленная на освоение новых рынков и услуг, применяемая в тех случаях, когда традиционное производство не позволяет достичь главной цели - получения прибыли.
В практике предприятий сферы городских пассажирских перевозок РФ диверсификация активно применяется на протяжении довольно длительного времени. Но диверсификация рассматривается лишь как вынужденная мера для выхода предприятия из кризисного состояния, вызванного отсутствием спроса на традиционный ассортимент работ и услуг. В предприятиях городских пассажирских перевозок, прибегающих к осуществлению диверсификации, в большинстве случаев наблюдается отсутствие четкой стратегии, организационно-технической и управленческой структуры [7].

Отметим также, что маркетинговая стратегия продвижения инноваций на предприятиях городских пассажирских перевозок в основе своей должна формироваться и реализовываться инструментами маркетинга - концепцией маркетинга инноваций, с использованием функций маркетинга инноваций, адаптированных для применения в сфере городских пассажирских перевозок (таблица 3).

Стратегическое целеполагание на маркетинг инноваций при разработке, реализации маркетинговых стратегий городских пассажирских перевозок определило необходимость концептуальной модели управления маркетингом инноваций в городских пассажирских перевозках. В сфере городских пассажирских перевозок концептуальная модель управления маркетин-

Таблица 2. Матрица PEST-анализ предприятий городских пассажирских перевозок (составлено авторами)

\begin{tabular}{|c|c|c|c|}
\hline Политика & $P(0,3)$ & Экономика & $E(0,3)$ \\
\hline $\begin{array}{l}\text { Подверженность руководителя пред- } \\
\text { приятия мнению высшего руковод- } \\
\text { ства }\end{array}$ & 4 & Нестабильный курс рубля & 4 \\
\hline $\begin{array}{l}\text { Несовершенство государственной } \\
\text { политики в области пассажирских } \\
\text { перевозок }\end{array}$ & 5 & Рост уровня и темпов инфляции & 3 \\
\hline $\begin{array}{l}\text { Принятие государством непредвиден- } \\
\text { ных новых законов }\end{array}$ & 4 & Высокие ставки по кредитам & 4 \\
\hline Социум & $\mathrm{S}(0,2)$ & Технологии & $\mathrm{T}(0,2)$ \\
\hline $\begin{array}{l}\text { Низкий уровень квалифицированных } \\
\text { кадров на рынке труда }\end{array}$ & 4 & $\begin{array}{l}\text { Высокий уровень распространения } \\
\text { новых технологий }\end{array}$ & 4 \\
\hline Высокий уровень текучести кадров & 3 & $\begin{array}{l}\text { Непрерывное обновление и модерниза- } \\
\text { ция транспортных средств }\end{array}$ & 3 \\
\hline $\begin{array}{l}\text { Отток молодых перспективных специ- } \\
\text { алистов в другие отрасли }\end{array}$ & 3 & $\begin{array}{l}\text { Появление новых экологических норм, } \\
\text { степени безопасности }\end{array}$ & 5 \\
\hline
\end{tabular}

Примечание: 0 - полное отсутствие влияния внешнего фактора, 1 - очень слабое влияние, 2 - слабое влияние, 3 - незначительное влияние, 4 - среднее влияние, 5 - сильное влияние 


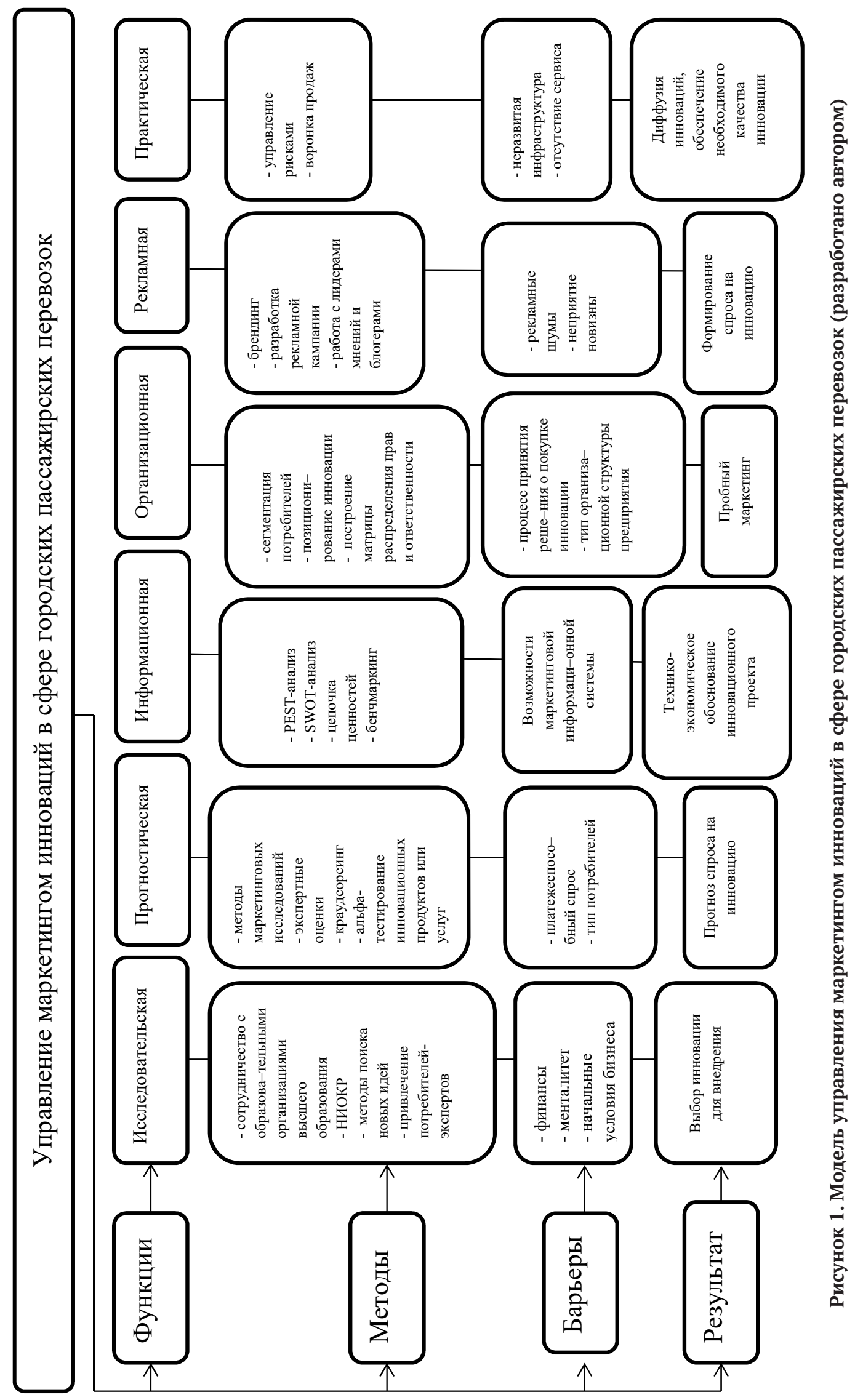


Таблица 3. Функции концепции маркетинга инноваций для городских пассажирских перевозок (составлено автором)

\begin{tabular}{|l|l|}
\hline \multicolumn{1}{|c|}{ Функция } & \multicolumn{1}{c|}{ Значение } \\
\hline Исследовательская & $\begin{array}{l}\text { Изучение потребностей, ожиданий, восприятий целевой аудитории городских } \\
\text { пассажирских перевозок, поиск инновации }\end{array}$ \\
\hline Прогностическая & $\begin{array}{l}\text { Изучение и предсказание возможных реакций целевой аудитории от внедрения } \\
\text { перспективной инновации в ближайшей перспективе }\end{array}$ \\
\hline Информационная & $\begin{array}{l}\text { Сбор сведений об инновационных продуктах и технологиях с учетом их востребо- } \\
\text { ванности со стороны целевой аудитории, перевозчиков, вышестоящих организа- } \\
\text { ций и инвесторов }\end{array}$ \\
\hline Организационная & $\begin{array}{l}\text { Объединение управленческих, законодательных, экономических, производствен- } \\
\text { ных и других аспектов для реализации инновационных проектов в городских } \\
\text { пассажирских перевозках }\end{array}$ \\
\hline Рекламная & $\begin{array}{l}\text { Разработка комплексной системы продвижения инноваций в сфере городских } \\
\text { пассажирских перевозок }\end{array}$ \\
\hline Практическая & $\begin{array}{l}\text { Обеспечение эффективной реализации инновационных проектов в сфере город- } \\
\text { ских пассажирских перевозок }\end{array}$ \\
\hline
\end{tabular}

гом состоит из взаимосвязанных между собой блоков - исследовательского, прогностического, информационного, организационного, рекламного и практического. Каждый блок представлен функцией, и реализуется определенными методами, при наличии барьеров для получения конкретного результата. Концептуальная модель адекватно отражает сущность управления маркетингом инноваций в сфере городских пассажирских перевозок (рисунок 1).

Маркетинговая деятельность предприятий в сфере городских пассажирских перевозок многогранна, со своими специфическими особенностями, усложняющими процесс развития системы городских пассажирских перевозок. Представленная модель управления маркетин- гом инноваций в сфере городских пассажирских перевозок позволит, используя функции маркетинга инноваций, кардинально предусмотреть возможные негативные последствия при маркетинговом планировании деятельности предприятий городских пассажирских перевозок. Данная модель позволит обеспечить координацию и оптимизацию работы городских пассажирских перевозок, а также транспортную и ценовую доступность для потребителей услуг - населения города. Это окажет значительное влияние на улучшение качества обслуживания потребителей, повышение эффективности использования транспортных средств и сокращение материальных и трудовых затрат на эксплуатацию.

\section{Библиографический список}

1. Лужнова Н.В., Карелин Н.В. Система управления инновационными процессами на предприятии // Современные тенденции развития науки и образования. 2016. Том 5. С. 19-26.

2. Лужнова Н.В., Карелин Н.В. К вопросу о внедрении инноваций в сфере общественного пассажирского транспорта // Молодой ученый. 2017. № 7(111). С. 887-889.

3. Калиева О.М., Фролова О.В. Маркетинг инноваций как инструмент успешного бизнеса // Вестник ОГУ. 2012. № 13. С. 175-179.

4. Калиева О.М., Карелин Н.В. Основные направления перспективного развития городских пассажирских перевозок: теория и практика применения методов обследования городских пассажирских перевозок // Juvenis Scientia. 2020. Toм 6. № 1. C. 8-10.

5. Karelin N.V., Kalieva O. M. Marketing Management in Urban Passenger Transportation Innovations // International Journal of Economics and Business Administration. 2019. Vol. VII. Special Issue 2. P. 211-220.

6. Вдовина С.Б. SWOT-анализ инновационного проекта // ИТпортал. 2014. № 4(4). С. 1-4.

7. Князев И. С. Автоматизация бизнес-процессов - потенциал для транспортных предприятий // Инновации транспорта. 2016. № 4(26). С. 12-15. 
8. Федеральный закон «Об организации регулярных перевозок пассажиров и багажа автомобильным транспортом и городским наземным электрическим транспортом в Российской Федерации и о внесении изменений в отдельные законодательные акты Российской Федерации» от 13.07.2015 г., № 220-Ф3 [Электронный ресурc]. URL: http://www.consultant.ru/document/cons_doc_LAW_182659/ (дата обращения 15.08.2019).

9. Муниципальная программа «Развитие пассажирского транспорта на территории города Оренбурга на 2017-2020 годы» [Электронный ресурс]. URL: http://orenburg.ru/activities/tselevye_programmy/2017/2.4.pdf (дата обращения 06.04.2020). 